\title{
Kinetics and Mechanism of Oxidation of Tartaric Acid by N-Chloronicotinamide (NCN)
}

\author{
L. Pushpalatha \\ Postgraduate and Research Department of Chemistry, \\ National College, Trichy - 620 001, Tamil Nadu, India \\ E-mail address: lathaa_ramesh@yahoo.com
}

Keywords: Tartaric acid; N-Chloronicotinamide; oxidation; mechanism

\begin{abstract}
The oxidation of tartaric acid by N-chloronicotinamide in the presence of $\mathrm{HClO}_{4}$ is studied. First order kinetics with respect to NCN is observed. The kinetics results indicate fractional order dependence about [tartaric acid]. Inverse first order in [nicotinamide] and inverse fractional order about $\left[\mathrm{H}^{+}\right]$are noted. Rate of the reaction increases with a decrease in the percentage of acetic acid. The values of rate constants observed at four different temperatures were utilized to calculate the activation parameters. A suitable mechanism consistent with the experimental findings has been proposed.
\end{abstract}

\author{
Abbreviations \\ NCN N-Chloronicotinamide \\ TA Tartaric acid \\ NA Nicotinamide
}

\section{INTRODUCTION}

The kinetics of the oxidation of hydroxy acids has been studied with a number of oxidizing agents like potassium bromate, hexamethylenetetraminebromine, sodium Nchlorobenzenesulfonamide, N-bromoacetamide, ditelluratocuprate(III), 2,2- bipyridium chlorochromate, benzo-dipteridine etc. Although hydroxy acids have been utilized for a number of catalyzed reactions, nobody has examined the role of catalysts in NBN oxidation of hydroxy acids. Malic acid is a key intermediate in the major biochemical energy-producing cycle in cells, known as the Kreb's cycle, it takes place in the cells mitochondria in most living organisms. The body synthesizes malic acid during the process of converting carbohydrates to energy. Preliminary evidence suggests that individuals with the disease fibromyalgia (a disorder that involves fatigue and pain in the muscles) might have difficulty in creating or utilizing malic acid. Such a deficiency could interfere with normal muscle function.

A.K. Singh [1] studied the kinetics and mechanism of oxidation of some hydroxy acids by Nbromoacetamide.

Chand Waqar [2] investigated the mechanism of Ru(III)-catalysed oxidation of glycollic and mandelic acids with $\mathrm{N}$-bromosuccinimide in acidic media.

Pradeep K. Sharma [3] reported the oxidation of some $\alpha$-hydroxy acids by tetraethylammonium chlorochromate.

Ajaya Kumar Singh[4] followed the kinetic and mechanistic study on the oxidation of hydroxy acids by N-bromophthalimide in the presence of a micellar system. E.V. Sundaram[5] explained the oxidation of $\alpha$-hydroxy acids with Quinolinium Dichromate .

Asim K Das[6] studied the micellar effect on the reaction of Chromium(VI) oxidation of some representative alpha-hydroxy acids in the presence and absence of 2,2'-bipyridyl in aqueous acid media. 
A perusal of literature shows that the reactivity of $\mathrm{N}$-chloronicotinamide $(\mathrm{NCN})$ could be compared with other N-haloimide such as N-bromosuccinimide (NBS) and N-bromosaccharin (NBSa). There are several reports available in the literature on the oxidation of alpha-hydroxy acids by oxidants such as N-bromosuccinimide,

N-bromoacetamide, potassium bromate, N-bromobenzenesuphonamide, and iodate[7]. However, the details of oxidation of tartaric acid by N-chloronicotinamide are yet to be explored. This encouraged the systematic kinetic study on the oxidation of tartaric acid by NCN in aqueous acetic acid medium.

\section{EXPERIMENTAL}

\subsection{Materials}

N-Chloronicotinamide $(\mathrm{NCN})$ was prepared by the reported method [8]. Standard solution of NCN was prepared afresh in water and its purity was checked iodometrically. Tartaric acid ((Merck) was used. $\mathrm{HClO}_{4}$ (A.R. grade) diluted with double distilled water and was standardized via acid-base titration. All other standard solutions of $\mathrm{NaClO}_{4}, \mathrm{KCl}, \mathrm{KBr}$ and nicotinamide were prepared using double distilled water. Double distilled water was distilled over $\mathrm{KMnO}_{4}$ in an all glass (Pyrex) distillation set up. Distilled acetic acid was used throughout the experiment.

\subsection{Kinetic Measurements}

The solution of tartaric acid and oxidant were kept in black coated bottles separately. These solutions were kept in the thermostat to attain the thermostatic temperature. The appropriate quantity of oxidant was added to the substrate containing other reagents and the reaction bottle was shaken well. The reaction was followed potentiometrically by setting up a cell made up of the reaction mixture into which the platinum electrode and reference electrode(SCE) were dipped. The e.m.f of the cell was measured periodically using a Equip-Tronics (EQ-DGD) potentiometer. The reactions were studied at constant temperature $35^{\circ} \mathrm{C}$. Different studies such as variation of tartaric acid, oxidant $(\mathrm{NCN})$, perchloric acid, sodium perchlorate, nicotinamide and temperature were carried out. The reaction was carried out under pseudo-first order condition ([tartaric acid] $>>[N C N])$. The pseudo-first order rate constants computed from the linear $\left(r^{2}>0.9990\right)$ plots of log $\left(\mathrm{E}_{\mathrm{t}}-\mathrm{E}_{\infty}\right)$ against time. Duplicate kinetic runs showed that the rate constants were reproducible within $\pm 3 \%$. The course of the reaction was studied for more than two half-lives.

\subsection{Stoichiometry}

The reaction mixture containing a known excess of $[\mathrm{NCN}]>>$ [tartaric acid] was kept in the presence of $\mathrm{HClO}_{4}$ and $\mathrm{Hg}(\mathrm{OAc})_{2}$ at $40^{\circ} \mathrm{C}$ for $72 \mathrm{~h}$. After completion of the reaction, the unconsumed NCN was calculated iodometrically. It was found that nearly 2 moles of NCN were consumed for each mole of tartaric acid.

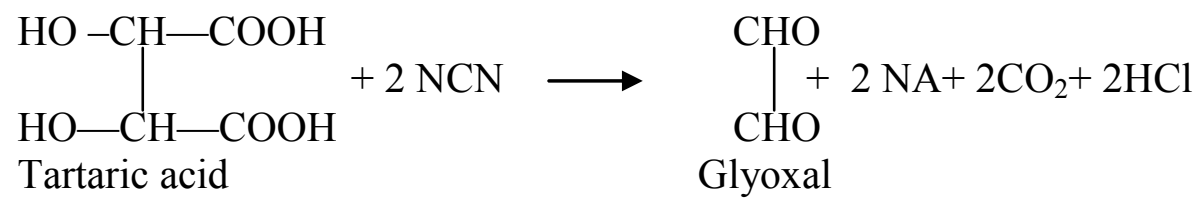

\subsection{Product Analysis}

The presence of glyoxal as the main oxidation product was detected by the spot test [9] and the 2,4dinitrophenylhydrazine method [10].

\section{RESULTS}

The kinetic results for the oxidation of tartaric acid by $\mathrm{N}$-Chloronicotinamide $(\mathrm{NCN})$ can be summarized as follows. The kinetic studies were carried out under pseudo-first order conditions with [tartaric acid] $>>[\mathrm{NCN}]$. 
The kinetics of the oxidation of tartaric acid by $\mathrm{NCN}$ in presence of $\mathrm{HClO}_{4}$ was investigated at several initial concentrations of the reactant. The reaction was of first order linearity of a plot of log $[\mathrm{NCN}]$ versus time for tartaric acid. The rate constants at different initial $[\mathrm{NCN}]$ are reported.

Table 1- Effect of variation of $[\mathrm{NCN}]$ on reaction rate

$$
\begin{gathered}
{[\text { Tartaric acid }]=0.03 \mathrm{~mol} \mathrm{dm}^{-3}, \quad\left[\mathrm{HClO}_{4}\right]=0.1 \mathrm{~mol} \mathrm{dm}^{-3},} \\
\text { AcOH: } \mathrm{H}_{2} \mathrm{O}(1: 4), \quad\left[\mathrm{NaClO}_{4}\right]=0.1 \mathrm{~mol} \mathrm{dm}^{-3}, \quad \text { Temp. }=308 \mathrm{~K}
\end{gathered}
$$

\begin{tabular}{|c|c|}
\hline $\begin{array}{c}{[\mathbf{N B N}]} \\
\mathbf{1 0}^{\mathbf{4}} \mathbf{~ m o l d m}^{-3}\end{array}$ & $\mathbf{1 0}^{\mathbf{5}} \mathbf{k}_{\mathbf{o b s}} \mathbf{~ s e c ~}^{\mathbf{- 1}}$ \\
\hline 1.0 & 35.03 \\
\hline 1.5 & 23.48 \\
\hline 2.0 & 17.47 \\
\hline 2.5 & 14.08 \\
\hline 3.0 & 11.82 \\
\hline 4.0 & 9.08 \\
\hline 5.0 & 7.17 \\
\hline
\end{tabular}

Table 1 summarizes the pseudo first order rate constant's dependence on the NCN concentration. It was observed that, with the increase in initial $\mathrm{NCN}$ concentration, the value of rate constant decreased. At a constant value of $\mathrm{NBN}, \mathrm{HClO}_{4}$, the rate constant was determined at different initial concentrations of tartaric acid ranging from $5 \times 10^{-3}$ to $50 \times 10^{-3} \mathrm{~mol} \mathrm{dm}^{-3}$. Table 2 summarizes the pseudo first order rate constant's dependence on tartaric acid concentration. The rate constant, increased with increasing [tartaric acid]. The plot of log $\mathrm{k}$ versus $\log$ [tartaric acid] was linear with a slope of less than unity showing fractional order dependence on [tartaric acid]. Furthermore, a plot of $\log \mathrm{k}$ versus [tartaric acid] was linear with an intercept on y axis, confirming the fractional order dependence on substrate. The rate constant $\mathrm{k}$ decreased with increase in $\left[\mathrm{HClO}_{4}\right]$ from $5 \times 10^{-3}$ to $50 \times 10^{-3} \mathrm{~mol} \mathrm{dm}^{-3}$ (Table 2). This may be due to protonation of the substrate. The plot of $\log \mathrm{k}$ versus $\log \left[\mathrm{HClO}_{4}\right]$ is linear with negative slope. The slope being less than unity indicates inverse fractional order dependence on $\left[\mathrm{HClO}_{4}\right]$. Successive addition of nicotinamide (as one of the oxidation products of $\mathrm{NCN}$ ) to the reaction mixture showed a decreasing effect on the rate of oxidation of tartaric acid. Addition of $\mathrm{NaClO}_{4}$ (to study the effect of ionic strength) in the reaction mixture showed an insignificant effect on the rate of oxidation. In order to find the effect of dielectric constant (polarity) of the medium on the rate, the oxidation of tartaric acid by NCN was studied in aqueous acetic acid mixtures of various compositions (Table 2). The data clearly reveal that the rate of reaction increases with a decrease in the percentage of acetic acid, i.e., increasing dielectric constant or polarity of the medium leads to the inference that there is a charge development in the transition state involving a more polar activated complex than the reactants [11]. 
Table 2- Effect of variation of [Tartaric acid], $\left[\mathrm{HClO}_{4}\right]$ and the dielectric constant on reaction rate

$[\mathrm{NCN}]=0.00015 \mathrm{~mol} \mathrm{dm}^{-3} \quad\left[\mathrm{NaClO}_{4}\right]=0.1 \mathrm{~mol} \mathrm{dm}^{-3}$,

Temp. $=308 \mathrm{~K}$

\begin{tabular}{|c|c|c|c|}
\hline $10^{3}[\mathrm{TA}]$ & $10^{3}\left[\mathrm{HClO}_{4}\right]$ & $\begin{array}{c}\mathrm{CH}_{3} \mathrm{COOH} \\
\%(\mathrm{v} / \mathrm{v})\end{array}$ & $\begin{array}{c}10^{5} \mathrm{k}_{\text {(obs) }} \\
\mathrm{sec}^{-1}\end{array}$ \\
\hline 5 & 10 & 20 & 5.59 \\
\hline 10 & 10 & 20 & 9.72 \\
\hline 20 & 10 & 20 & 16.72 \\
\hline 25 & 10 & 20 & 19.93 \\
\hline 30 & 10 & 20 & 23.57 \\
\hline 40 & 10 & 20 & 29.03 \\
\hline 50 & 10 & 20 & 34.78 \\
\hline 30 & 5 & 20 & 34.44 \\
\hline 30 & 10 & 20 & 23.55 \\
\hline 30 & 20 & 20 & 16.47 \\
\hline 30 & 25 & 20 & 14.66 \\
\hline 30 & 30 & 20 & 13.27 \\
\hline 30 & 40 & 20 & 11.37 \\
\hline 30 & 50 & 20 & 10.03 \\
\hline 30 & 10 & 20 & 23.58 \\
\hline 30 & 10 & 25 & 20.93 \\
\hline 30 & 10 & 30 & 18.15 \\
\hline 30 & 10 & 40 & 13.17 \\
\hline 30 & 10 & 50 & 8.58 \\
\hline & & & \\
\hline
\end{tabular}

In the present case, $\mathrm{KBr}$ has no effect on the reaction rate where as the rate of reaction increased with an increasing concentration of $\mathrm{KCl}$.

\subsection{Effect of temperature}

Increase in temperature increases the rate of oxidation and plot of $\log \mathrm{k}_{\mathrm{obs}}$ Vs reciprocal of temperature is linear. The oxidation of tartaric acid by NCN was studied at different temperatures $(303 \mathrm{~K}$ to $323 \mathrm{~K})$ (Table 3 ) and the activation parameters were evaluated (Table 4). Activation parameters are believed to provide useful information regarding the environment in which chemical reactions take place.

Table 3-Effect of Temperature on reaction rate

[Tartaric acid $]=0.03 \mathrm{~mol} \mathrm{dm}^{-3}\left[\mathrm{HClO}_{4}\right]=0.01 \mathrm{~mol} \mathrm{dm}^{-3}$, $[\mathrm{NCN}]=0.0015 \mathrm{~mol} \mathrm{dm}^{-3} \quad\left[\mathrm{NaClO}_{4}\right]=0.1 \mathrm{~mol} \mathrm{dm}^{-3}$, $\mathrm{AcOH}: \mathrm{H}_{2} \mathrm{O}(1: 4)$

\begin{tabular}{|c|c|}
\hline $\begin{array}{c}\text { Temperature } \\
\mathbf{K}\end{array}$ & $\mathbf{1 0}^{\mathbf{5}} \mathbf{k}_{\mathbf{o b s}} \mathbf{s e c}^{\mathbf{- 1}}$ \\
\hline 303 & 18.88 \\
\hline 308 & 23.52 \\
\hline 313 & 28.68 \\
\hline 318 & 34.95 \\
\hline 323 & 42.61 \\
\hline
\end{tabular}


Table 4- Activation Parameters

\begin{tabular}{|c|c|c|c|c|}
\hline Substrate & $\mathrm{E}_{\mathrm{a}} \mathrm{kJmol}^{-1}$ & $\Delta \mathbf{H}^{\#} \mathbf{k J m o l}^{-1}$ & $\Delta \mathbf{S}^{\#} \mathbf{J ~ K}^{-1} \mathbf{m o l}^{-1}$ & $\Delta \mathbf{G}^{\#} \mathbf{k J m o l}^{-1}$ \\
\hline Tartaric acid & $14: 31$ & 16.87 & -168.6 & 66.24 \\
\hline
\end{tabular}

\subsection{Test for Free Radicals}

To test for the presence of free radicals in the reaction, the reaction mixture containing acrylamide was kept for $24 \mathrm{~h}$ in an inert atmosphere. When the reaction mixture was diluted with methanol, the formation of a precipitate was not seen. This suggests that there is no possibility of formation of free radicals in the reaction.

\section{MECHANISM}

It has been reported [12] earlier that $\mathrm{NCN}$ is a stable oxidizing and chlorinating agent because of the large polarity of the $\mathrm{N}-\mathrm{Cl}$ bond. $\mathrm{NCN}$, like other similar $\mathrm{N}$-haloimides, may exist in various forms in an acidic medium, that is, free $\mathrm{NCN}$, protonated $\mathrm{NCN}, \mathrm{Cl}^{+}, \mathrm{HOCl},\left(\mathrm{H}_{2} \mathrm{OCl}\right)^{+}$according to the following equilibria.

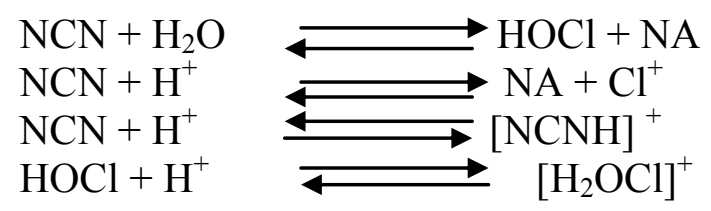

Addition of nicotinamide to the reaction mixture decreases the rate of oxidation in acidic media suggesting that the pre-equilibrium step involves a process in which nicotinamide is one of the products. When $\mathrm{NCN}$ or $(\mathrm{NCNH})^{+}$is assumed as the reactive species, the derived rate laws fail to explain the negative effect of nicotinamide, hence neither of these species can be considered as reactive species. When $\left(\mathrm{H}_{2} \mathrm{OCl}\right)^{+}$is taken as the reactive species, the rate law obtained shows first order kinetics with respect to hydrogen ion concentrations contrary to the observed negative fractional order in $\mathrm{HClO}_{4}$; although it fully explains the negative effect of nicotinamide. Therefore, the possibility of cationic bromine $\left(\mathrm{Cl}^{+}\right)$as a reactive species is also ruled out. Thus, the only choice left is $\mathrm{HOCl}$, which, when considered as the reactive species of $\mathrm{NCN}$, leads to a rate law capable of explaining all the kinetics observations and other effects. Hence, in the light of kinetic observations, $\mathrm{HOCl}$ can safely be assumed to be the main reactive species of NCN for the present reaction. On the basis of the above experimental findings and taking $\mathrm{HOCl}$ to be the most reactive species of NBN, the following scheme can be proposed for the kinetics of oxidation of tartaric acid by NCN in acidic medium.

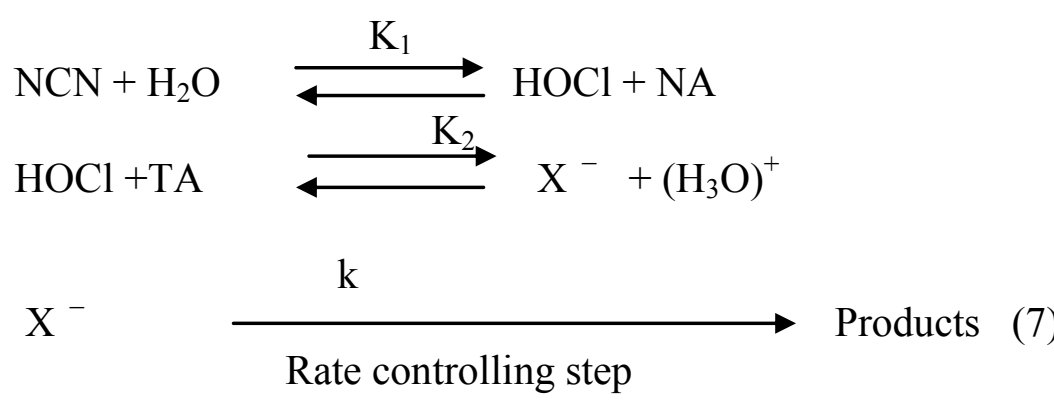

According to above scheme, the rate of disappearance of NBN is given as 
$-\frac{d[N B N]}{d T}=\frac{k K 1 K 2[T A][N B N] T O T A L}{[N A][H+]+K 1 K 2[T A]}$

where

$[\mathrm{NCN}]$ тотAL $=[\mathrm{NCN}][\mathrm{NA}]\left[\mathrm{X}^{-}\right]$

The above rate law is in good agreement with the experimental results.

\section{CONCLUSION}

At the end of this study, it is evident that the reaction rates are enhanced by increase in [tartaric acid] and temperature. Added nicotinamide retards the rate. $\mathrm{HOCl}$ is the reactive intermediate leading to product. Glyoxal is the product of oxidation. Suitable mechanism in compliance with experimental observations was proposed and the rate law was derived.

\section{AKNOWLEDGEMENTS}

The author gratefully acknowledges her husband Mr. A. Ramesh for the physical and moral support.

\section{References}

[1]. Madhu Saxena, Ranjana Gupta, Amar Singh, Bharat Singh, Singh A. K., Journal of Molecular Catalysis. 65(3) (1991) 317 .

[2]. Chand Waqar, Bharat Singh, Sharma J.P., Journal of Molecular Catalysis. 60(1) (1990) 49.

[3]. Preeti Swami, Yajurvedi D., Mishra P., Pradeep K. Sharma, International Journal of Chemical Kinetics. 42(1) (2010) 50.

[4]. Patil Sangeeta, Katre Y. R., Ajaya Kumar Singh, Journal of Surfactants and Detergents.10(3) (2007) 175.

[5]. Kailasa Aruna, Prerepa Manikyamba, Embar Venkatachari Sundaram, Collection of Czechoslovak Chemical Communications, 58(7) (1978) 1624.

[6] .Ruhidas Baeyen, Mohirul Islam, Asim K Das, Indian Journal of Chemistry. 48A (2009) 1055.

[7]. Sangeeta Patil, Katre Y. R., Ajaya Kumar Singh, Colloids and Surfaces. A: Physicochem.

Eng. Aspects, 308 (2007) 6.

[8]. Vivekanandan K, Nambi K., Indian J. Chem Sect. B. 35 (1996) 1117.

[9]. F. Feigl, Spot test in organic analysis, Elsevier, New York, 425 (1975).

[10]. Mathur A, Sharma V, Banerji K.K., Ind J Chem., 27A (1988) 123.

[11] .Laidler K. J., Tata Mc. Graw Hill, New Delhi (1965) 229.

[12]. (a) Vivekanandan K., Oxid Commun. 27(1) (2004) 195.

(b) Ramasamy V, Nambi K., Asian J Chem. 18 (2006) 2605.

(c) Mathiyalagan N., Oriental Journal of Chemistry. 21 (2005) 125.

(d) Ramkumar B., Oxid Commun . 24(4), (2001) 554.

(e) Mathiyalagan N.,. J Indian Chem Soc. 82 (2005) 1.

(f) Mathiyalagan N., Mapana Journal of Sciences. 3, (2005) 1.

(g)Vivekanandan K, Nambi K., J Indian Chem Soc. 76, (1999) 198.

(h) Pushpalatha L, Vivekanandan K., J Indian Chem Soc. 87, (2010) 1221.

(i) Pushpalatha L., Afinidad 68 (2011) 511.

(j) ) Pushpalatha L, Vivekanandan K., Oxid. Commun. 36(3) (2013) 583.

(k) ) Pushpalatha L, Vivekanandan K., Oxid. Commun. 36(3) (2013) 573.

(1) Jabbar S.F.A , Rao V.S ., Ind J Chem. 33A ((1994) 69. 